\title{
DOCUMENTOS NARRATIVOS Y PRÁCTICA REFLEXIVA EN LA FORMACIÓN DE PROFESORES
}

\author{
NARRATIVE DOCUMENTS AND \\ REFLECTIVE PRACTICE IN \\ TEACHER TRAINING
}

\author{
Rebeca Anijovich \\ Graciela Cappelletti
}

Mg en Formación de Formadores. Profesora adjunta en la cátedra de Observación y Práctica de la Enseñanza del Profesorado, Ciencias Jurídicas de la Facultad de Derecho, Universidad de Buenos Aires. Directora del Profesorado Universitario de la Universidad de San Andrés. Investigadora de la Universidad de Buenos Aires en el marco de sus proyectos de investigación UBACyT.

ra@anijovich.net

Mg en Didáctica. Jefa de Trabajos Prácticos en la cátedra de Observación y Práctica de la Enseñanza del Profesorado, Ciencias Jurídicas de la Facultad de Derecho, Universidad de Buenos Aires. Directora de la Licenciatura en Ciencias de la Educación de la Universidad de San Andrés. Investigadora de la Universidad de Buenos Aires en el marco de sus proyectos de investigación UBACyT.

gracielacappelletti@derecho.uba.ar 


\section{RESUMEN}

En este trabajo se relevan, sistematizan y analizan categorías teóricas específicas, en el marco de la conceptualización de la docencia como práctica reflexiva. Se enfatiza la utilización de dispositivos narrativos: autobiografías y diarios de formación. Se ha partido de la recopilación de autobiografías escolares y diarios de formación realizados por los abogados de la Facultad de Derecho de la Universidad de Buenos Aires, que han cursado el Profesorado en Ciencias Jurídicas.

Estas producciones suponen una valoración de la práctica docente, en tanto espacio de producción de saberes, y el reconocimiento a los profesores como profesionales que tienen teorías implícitas y experiencias que pueden contribuir a la constitución de una base sistematizada de conocimientos sobre la enseñanza.

Palabras clave: Reflexión, dispositivos, autobiografías, diarios de formación.

\section{ABSTRACT}

This research has attempted to relieve, organize, analyze and formulate specific theoretical categories in the framework of the conceptualization of teaching as reflective practice. It focuses on the use of narrative devices: autobiographies and training journals. It has started from the collection of school autobiographies and training journals carried out by the lawyers of the Faculty of Law of the University of Buenos Aires who have studied the Faculty of Legal Sciences.

These productions suppose an evaluation of the teaching practice, as a space for the production of knowledge and the recognition of professors as professionals who have implicit theories and experiences that can contribute to the constitution of a systematized base of knowledge about teaching.

Keywords: Reflection, Devices, Autobiographies, Training Journals. 
Las autobiografías constituyen el acto sutil de poner una muestra de recuerdos episódicos en una densa matriz de recuerdos semánticos organizados y culturalmente esquematizados.

Bruner y Weisser (1991:185).

Las investigaciones de las últimas décadas sobre los géneros narrativos y los diferentes modos del testimonio personal y autobiográfico evidencian cómo las personas toman mayor conciencia de sí y de su mundo, cómo aprenden a tener una mayor comprensión de sí mismas a medida que ejecutan el acto de la lectura, o incrementan ese saber de sí a medida que se internan en el relato de sus propias experiencias. En este orden de cosas y apoyándose en estas evidencias, Pinar y Grumet (1976), en su libro sobre la reforma del currículum, plantean la necesidad de recuperar la propia memoria como un antecedente autobiográfico de suma importancia para la vida profesional. En sus trabajos, invitan a los docentes a revisar sus propias prácticas indagando en la perspectiva temporal que reviste toda autobiografía, en este caso la propia, a través de un método que consiste en articular, complejizar y replantear el ejercicio y el compromiso con la tarea docente a la luz de narrar separadamente los tres planos temporales: las experiencias pasadas, la situación presente y las imágenes futuras.

Encontramos aquí un ejemplo de la abundante bibliografía que se ha elaborado últimamente en el campo de los estudios sobre «narratología», tema que nos interesa con respecto a la auto comprensión del sujeto y sus consecuencias para la tarea pedagógica. La bibliografía incluye un arco muy vasto, desde las historias orales o escritas en las que los individuos dan cuenta de cierta comprensión de situaciones (Riessman, 1993; Lawrence-Lightfoot y Davis, 1997), hasta los trabajos en los que se exploran aspectos metodológicos de la narración (Richardson, 1997). 


\section{LA NARRACIÓN: UN TÉRMINO EN BUSCA DE SU DEFINICIÓN}

Etimológicamente, la palabra narración, acción y efecto de narrar, proviene de gnarus, en latín, que significa «experto, conocedor». De acuerdo con el diccionario de María Moliner (1991), el que narra es justamente quien tiene la habilidad para decir o escribir una historia, o explicar cómo ha ocurrido cierto suceso. En el Diccionario ideológico de la lengua española, «narración se aplica a una de las partes del discurso retórico, en que se refieren los hechos que han de servir de base para la argumentación y así permitir un esclarecimiento del asunto de que se trata» (Casares, 1984, p. 254). Como se ve, aquí priva un enfoque juridicista. Pero en el Diccionario de retórica y poética de Helena Beristain (1995), la narración se refiere a «textos pertenecientes a diversos géneros literarios en los que se emplea la técnica narrativa» (p. 123); siguiendo al etnólogo Claude Brémond, lo cita indicando que es un relato en el que se presenta «una sucesión de acontecimientos que ofrecen interés humano y poseen unidad de acción».

En el Diccionario de términos literarios (1990): «narración, del latín narratio-onis, acción de narrar: La actividad de narrar está profundamente arraigada en la vida del hombre, y forma parte de ella, bien como expresión de sus propias experiencias, o de acontecimientos externos que serán contados ya sea mediante la expresión oral o escrita» (pp. 255-256). Ahora bien el significado que el término «narración» tiene en la actualidad — sin olvidar la posible referencia a los diversos subgéneros narrativos - es el de contar una historia, el de producir un discurso narrativo, frente a la descripción, en la que la historia y el tiempo se paralizaban, y, entretanto, la descripción nos hablaba del escenario y las circunstancias en que se desarrollaba la historia. En la narración se produce un desarrollo de la acción a través del tiempo y se revelan distinciones, por ejemplo, entre el tiempo del relato y el tiempo real vivido por el narrador.

Por su parte, Gudmundsdottir (1998), profesora del Instituto Pedagógico de la Universidad de Trondheim, Noruega, define en la década del 90 a la narrativa como aquella que 
[...] se refiere a la estructura, el conocimiento y las habilidades necesarias para construir una historia. En lenguaje cotidiano, los términos historia y narrativa son sinónimos. Una historia tiene personajes; tiene comienzo, medio y fin; y se unifica por medio de una serie de eventos organizados. El conjunto se denomina trama o argumento (pp. 52-53).

Con el propósito de articular elementos comunes entre diversos expertos y con el fin de manejar una noción de narración apropiada para nuestro trabajo, encontramos narraciones desplegadas según diferentes modalidades y posibilidades compositivas, secuenciales y de sentido, sobre experiencias docentes a través del recuerdo de diversos eventos, anécdotas, personajes, circunstancias, climas, motivaciones, una cierta comprensión del mundo y una profundización en la conciencia de sí.

En general, podemos considerarlos como relatos de una persona a otra, real o imaginaria, pero en ocasiones también puede encarnarse en el discurso de un nosotros a un tú o a un vosotros, adoptando un curso lineal o espiralado. En estos relatos existe siempre un narrador (instancia textual distinta del personaje biográfico que cuenta) que se hace cargo del relato y de sus estrategias narrativas. Es quien conoce toda la historia y puede seleccionar eventos, secuencias, cambiar partes, omitir otras, dar cuenta de lo que le interesa o preocupa, dar el tono y proponer la voz y el estilo del contar, ya sea en forma oral o escrita. De ahí que las historias pueden ser objeto de múltiples interpretaciones y reinterpretaciones que, a su vez, dan origen a nuevas experiencias del sujeto. Un mismo hecho, incluso protagonizado por la misma persona, tiene significado diferente en distintas etapas de su vida o con una diferente intencionalidad. Por eso se afirma que el narrador es el que tiene el verdadero poder en el acto de narrar ya que, en definitiva, es quien teje y desteje los muchos hilos de la trama y la forma de lo que se relata.

Nos interesa esta perspectiva por el rol protagónico del docente como narrador, en tanto que decide qué y cómo relatar hechos de su ejercicio profesional, establece relaciones entre los diferentes acontecimientos de su historia de vida privada y profesional, y los puede situar en un contexto determinado. 


\section{LA NARRACIÓN ACERCA DE LA DOCENCIA}

Desde un punto de vista narrativo, y en atención a lo señalado acerca del narrador, es interesante notar que los docentes viven sus historias, piensan, perciben, imaginan y realizan elecciones morales de acuerdo con las estructuras narrativas y modalidades en que construyen su relato. Los trabajos que comienzan a indagar sobre la importancia de la narración y autorreflexión del docente, y su incidencia pedagógica, abren un área rica de posibilidades, toda vez que, hasta no hace mucho, las biografías orales y escritas eran subestimadas o consideradas como formas de representación de segundo orden que poco agregaban a las cuestiones de la enseñanza. Estas últimas posturas partían de una óptica conductista, ignorando el hecho de que todo acto pedagógico pone en juego una compleja dialéctica de saberes e intersubjetividad.

En este orden de ideas, Carretero y Atorresi (2004) señalan:

La modalidad narrativa también orienta emotivamente la comprensión de los sucesos. Se trata, por tanto, de un dispositivo de constitución de la subjetividad, en el que lo emotivo y lo cognitivo se interrelacionan. Así, resulta una estructura estructurante, humana y humanizante, que permite tanto la acción y la reacción de los hombres a través de la significación del mundo como la modificación y la creación de mundos posibles en un proceso que enlaza los planos intermental e intramental (p. 280).

En efecto, en la narración aparecen, junto con una dimensión cognitiva, y aunque no se los reconozca en forma explícita, aspectos emocionales del narrador, de la propia narración, del oyente o lector de la narración, como un aspecto a considerar en el trabajo con docentes, tonalidades de la sensibilidad y los sentimientos que no se deben ignorar si se incluye el análisis de las narraciones como dispositivos válidos de formación docente.

Desde el campo de la psicología cultural, Jerome Bruner (1990) plantea que las personas toman conciencia primariamente de sus vidas y la de sus semejantes cuando su comprensión existencial adopta la forma de un relato. Su hipótesis de base plantea que existe en el hombre una «facilidad o predisposición a organizar la experiencia de 
forma narrativa, mediante estructuras de tramas» (p. 57) y que, entonces, en las más diversas circunstancias, esta propensión narrativa - como forma embrionaria de dotar de sentido a las cosas-, surge naturalmente, cuando algún hecho o alguna situación no encajan con lo esperado o previsible y necesitan ser reorientadas, cifradas y acomodadas para que sea puesta en el carril de la realidad. Para Bruner (1987) las narrativas son una forma de organizar el conocimiento: lo describe y lo explica en relación con las intenciones humanas.

Si nos trasladamos al campo de la formación de docentes en servicio, podemos dar cuenta que en repetidas ocasiones, ante una situación inesperada, necesitan contar muchas veces la misma situación, casi como un modo de acercarse a lo que sucedió, de intentar comprender, compartir con otros o reafirmarse ante lo distinto, lo inédito o lo imprevisto. En este ejercicio de narración se pueden observar distintos niveles de reflexión acerca de lo relatado, ya sea como una mera descripción de lo sucedido, como un análisis crítico o una comprensión profunda de sí mismo. El pasaje, no lineal, de un nivel de reflexión a otro no es espontáneo, sino producto de un trabajo guiado, con intencionalidad, que necesita tiempo, espacio y dispositivos para su desarrollo.

Los relatos de los docentes no son neutros ni están despojados de sentimientos y reflexiones que exceden los conocimientos explícitos a los que los propios docentes pueden hacer referencia. Narrar acerca de la docencia nos permite conectarnos con la reflexión de los docentes, en tanto constituye una alternativa para «transparentar» aquellos pensamientos de difícil acceso directo.

El relato y la escritura de la experiencia a través de estrategias narrativas (Alliaud y Suarez 2011; Suarez 2011) favorecen según estos autores, las condiciones para la reflexión durante la acción y sobre lo que se hace con el fin de ser más consciente y transformarlo.

En el recorrido de las investigaciones relevadas, mencionamos dos investigaciones cuyos aportes dan cuenta de la diversidad de miradas acerca de la reflexión docente.

En la primera investigación, Cochram-Smith y Lytle (1990) estudian los lazos entre la docencia, y la investigación, y señalan un fenómeno 
revelador de las dificultades para una toma de conciencia del propio quehacer pedagógico. Afirman que en la base del conocimiento de los profesores están perdidas o acalladas sus propias voces, aquellas que desencadenan la comprensión, las preguntas que ellos mismos se formulan, los modos en que ejercitan la escritura, los marcos interpretativos que utilizan para comprender sus prácticas, y que son precisamente estas cuestiones las que aparecen como irresueltas en sus narrativas y reflexiones. Muchos de los investigadores no ejercen la docencia y muchos docentes no investigan y / o no documentan aquello que practican cotidianamente en las aulas, y esto dificulta la posibilidad de compartir y de hacer oír la voz de quien está llevando adelante una experiencia. Si bien no hablamos del mismo tipo o fuentes de saberes, los del investigador y de los docentes, el trabajo conjunto de ambos enriquece las producciones y permite que las voces de los docentes circulen también fuera de las paredes del aula.

Una segunda investigación que aporta ideas relevantes al tema de las narrativas y la enseñanza es la de Hunter McEwan y Kieran Egan (1997). Ellos consideran imprescindible aunar los aspectos cognitivos y afectivos. Señalan la coincidencia que encuentran entre la forma narrativa por un lado, y el pensamiento y la práctica educativos, por otro. Definen las narrativas como aquellas que

[...] forman un marco dentro del cual se desenvuelven nuestros discursos acerca del pensamiento y la posibilidad del hombre, y que proveen la columna vertebral estructural y funcional para muchas explicaciones específicas de ciertas prácticas educativas. Los relatos contribuyen a fortalecer la capacidad de los docentes para debatir acerca de cuestiones y problemas educativos. Además, dado que la función de la narrativa consiste en hacer inteligibles las acciones para los propios docentes y también para los que escuchan, el discurso narrativo es fundamental en los esfuerzos por comprender la enseñanza y el aprendizaje. Es necesario aprender más acerca de la narrativa y del papel que desempeñan las narraciones en la educación (p. 18).

En las dos investigaciones presentadas, se vislumbran algunas líneas comunes con respecto al conocimiento tácito: aquello que el 
docente tiene para aportar de sus experiencias y la narración como un modo de pensar en voz alta al dar a conocer, explicitar, y permitir transparentar algún aspecto de lo que denominamos reflexión, contribuyendo a una mayor conciencia y comprensión acerca del ejercicio de la docencia. En estas líneas de investigación se puede identificar una correlación entre la historia personal y profesional del docente.

El recorrido de una cantidad significativa de manifestaciones con propósitos auto testimoniales, nos advierte que la modalidad elegida por el relator de su vida —-según sea oral, escrita, pautada, espontánea, en autobiografías unitarias, parciales, focalizadas en ciertos temas, diarios con continuidades o interrupciones temporales, o ensayos de historias de vida con una intención objetiva-, nos aporta una primera información acerca del autor.

Connelly y Clandinin (1995) se proponen encontrar procedimientos de indagación del conocimiento práctico de los profesores que respeten sus características; el modo de lograrlo es a través de la narrativa, el relato y el concepto relacionado de imagen. Para estos autores, el conocimiento que se obtiene de la experiencia se organiza en imágenes, entendidas como componentes del conocimiento práctico personal de los docentes y como recurso para entender su pensamiento. Las describen y explican considerando que establecen relaciones entre la vida privada con la experiencia profesional, poseen un carácter histórico, una dimensión moral en la medida en que le otorga criterios al docente, relacionados con formación y experiencias para juzgar su propia práctica; están relacionadas con sentimientos personales.

En el año 2002, Clandinin presenta un artículo donde analiza y evalúa sus investigaciones efectuadas diez años antes (Connelly y Clandinin, 1995), señalando el tránsito del enfoque en las investigaciones: desde el conocimiento del docente como un conocimiento práctico, personal, hacia las historias vividas, que cobran sentido a través de la comprensión e interpretación de las narrativas en el contexto de una vida. El trabajo de campo, observando clases y entrevistando a docentes, es el que permite a Clandinin reorientar 
sus investigaciones, focalizándolas en el esfuerzo por conectar el desarrollo del saber pedagógico de los docentes con el desarrollo de sus vidas personales a través de los procesos de auto narración que profundizan su conciencia de sí, juntamente con la construcción de la identidad profesional. Las historias que oímos y las que contamos o nos contamos le proporcionan un sentido a la experiencia y contribuyen a organizar la memoria. De ahí que este investigador conceptualice las «historias vividas» por los docentes no solo como un modo de pensar acerca de su identidad, sino también como un modo de reorganizar sus conocimientos que posibilitan cambios en la práctica profesional y en las valoraciones personales.

En el mismo período, Freema Elbaz (2002) indica a través de sus investigaciones, que las narrativas encontraron una aplicación útil en la investigación educativa y describe tres tipos de narrativas: la narrativa en el currículum, la narrativa en la vida de los maestros y la narrativa de los investigadores acerca de las dos primeras.

En muchos relatos que investiga la autora, las descripciones permitieron a los docentes pasar de un conocimiento tácito a uno explícito, o entender algunas dimensiones de la realidad objetiva y subjetiva no conscientes hasta ese momento, lo cual significa un descubrimiento muy importante que incide en los programas de formación de docentes. Indudablemente estas investigaciones no estuvieron exentas de críticas, sobre todo atendiendo a las posibilidades de un manejo correcto por parte de los docentes de las teorías pedagógicas, a partir de tomar conciencia de las diversas dificultades de orden profesional y personal en el ejercicio de narraciones autobiográficas.

De lo que se trata entonces es de develar algo de lo que está oculto, que no es evidente ni se accede a través de la observación. Es necesario conversar, dialogar con uno mismo y con otros para explicitar e interpretar, con prudencia, esos conocimientos, considerando las diferencias entre hacerlo desde una mirada externa o desde la propia explicación del docente narrador de sus propias historias. 


\section{LOS DISPOSITIVOS DE FORMACIÓN PARA LA REFLEXIÓN BASADOS EN NARRACIONES}

Comprendemos al conjunto de dispositivos de formación docente como un modo particular de organizar las experiencias formativas, con el propósito de generar situaciones para que los sujetos que participan en él reflexionen, se adapten activamente y modifiquen a través de la interacción consigo mismos y / o con otros, adaptándose activamente a situaciones cambiantes, apropiándose de saberes nuevos, desarrollando disposiciones y construyendo capacidades para la acción (Anijovich y Cappelletti, 2011).

Los dispositivos narrativos consisten en la producción de relatos escritos como medio para acceder a la experiencia subjetiva de los estudiantes, para que éstos puedan tomar como objeto de reflexión su propia historia escolar, sus creencias, sus prejuicios, sus conocimientos previos y sus esquemas de acción adquiridos de modo consciente o no. En esta categoría incluimos la autobiografía escolar y el diario de formación.

Cabe destacar que en esta línea, en la actualidad, existe una fuerte incidencia en los programas de formación docente en los que se plantean narraciones escritas en forma de autobiografía profesional, de relato de lo acontecido en una clase o la identificación de dilemas relativos a la práctica docente. $\mathrm{Al}$ «poner en palabras» ideas, pensamientos, preguntas en un marco compartido con otros colegas / compañeros es posible aumentar el nivel de conciencia acerca de la enseñanza.

Las biografías, autobiografías, confesiones, memorias, diarios íntimos, y correspondencias dan cuenta, desde hace poco más de dos siglos, de esa obsesión de la humanidad por dejar huellas, rastros e inscripciones, de ese énfasis en la singularidad de los sujetos que es, a un mismo tiempo, búsqueda de trascendencia (Arfuch, 2002).

El hecho de que las ciencias comiencen recientemente a considerar el valor de los documentos personales no significa que a lo largo de la historia de la humanidad no hayan estado presentes. Podemos encontrar diferentes géneros de este tipo, como diversos modos de dejar registro de las experiencias vividas: historias orales, al principio, 
y luego diarios, cartas, literatura basada en hechos reales, fotografías, películas y correspondencia.

Cabe destacar que las narrativas autobiográficas son un recurso para reconstruir experiencias ya vividas, acciones ya realizadas; no son la acción misma, sino una versión que el autor de la acción proporciona, posteriormente, acerca de su propia acción ya pasada. Es así como uno de los rasgos que identifican a este tipo de narrativas es su carácter experiencial. Se narran experiencias vividas por el narrador, recordadas, interpretadas, en las que hay otros actores, pero siempre son experiencias de quien escribe. Otro de sus rasgos característicos es que son relatos. Un relato supone que el narrador dota de una estructura propia a su narración, construye una hilación singular y propia. Un tercer rasgo singular de estas narraciones es que son significativas socialmente. La estructura narrativa hace que lo experiencial pueda ser comprendido por un otro. Esto es, se produce una traducción de lo íntimo de las vivencias personales, a formas compartidas socialmente, por medio del lenguaje.

Las historias que oímos y las que contamos a otros, o a nosotros mismos, proporcionan un sentido singular a la experiencia, y contribuyen a organizar la memoria. De ahí que las «historias vividas» y contadas por los docentes no son solo un modo de pensar acerca de su identidad, sino también un modo de reorganizar sus conocimientos que posibilita cambios en la práctica profesional y en las valoraciones personales (Pinar, 1988).

Por eso, escribir y contar historias profesionales y personales se convierte en un instrumento poderoso en la formación de profesores. Se trata de provocar, a través de las narrativas, la reflexión sobre el conocimiento práctico y sobre la comprensión e interpretación del contexto de la propia vida. De este modo, se intenta conectar el desarrollo del saber pedagógico de los docentes con el desarrollo de sus vidas personales, a través de los procesos de auto narración que, junto con la construcción de la identidad profesional, profundizan el conocimiento sobre sí mismos.

En esta línea, Bolívar, Domingo y Fernández (2001), sostienen que cualquier propuesta de formación del profesorado debería empezar por recuperar, biográfico-narrativamente, el sujeto a formar, desde sus experiencias y recuerdos de su pasado, en el presente. El proceso 
formativo adquiere así los contornos de un proceso de construcción de la persona del profesor, como reapropiación crítica del pasado y de los contenidos profesionales adquiridos.

Otro de los dispositivos que consideraremos en este trabajo es el de los diarios de formación. En palabras de Zabalza ${ }^{1}$ (2007) podemos definirlos como «[...] los documentos en los que los profesores y profesoras recogen sus impresiones sobre lo que va sucediendo en sus clases». Esta definición intencionalmente amplia da cabida a distinto tipo de producciones que recogen contenidos con focos y estilos diferentes, y reflejan la perspectiva quien escribe. Al respecto, Porlán (1999: 64) define al diario como

[...] un instrumento metodológico cuya utilización periódica permite reflejar el punto de vista del autor sobre los procesos más significativos en los que está inmerso [...] Favorece también el establecimiento de conexiones significativas entre conocimiento práctico y conocimiento disciplinar, lo que permite una toma de decisiones más fundamentada.

Desde el punto de vista metodológico, los diarios forman parte de los enfoques y líneas de investigación basadas en documentos personales o narraciones autobiográficas. Estos enfoques son cualitativos y han adquirido una fuerte relevancia en la investigación educativa a partir de la década del 90. Si profundizamos el concepto de documento personal, encontramos que los diarios permiten registrar el flujo de acontecimientos cotidianos públicos y privados, en forma contemporánea desde la perspectiva subjetiva del diarista. Plummer y Cobelo (1989) mencionan que escribir un diario de formación se parece, en algún sentido, a escribir un diario íntimo o un diario de viaje, en la medida en que permite reflejar la experiencia subjetiva de quien escribe. Pero no solo es una catarsis o un registro, ya que el autor se convierte luego en lector de su propia historia, de su pensamiento objetivado, de su emoción olvidada y allí se reconoce, se redescubre o se da cuenta de algo nuevo sobre sí mismo. Al analizar el impacto de los diarios en los procesos formativos, Zabalza

1 El autor citado, utiliza la denominación "diario de clase", no obstante tomamos sus aportes porque al profundizar en su formulación de este concepto, observamos que la caracterización coincide con el dispositivo que hemos dado en llamar "diario de formación". 
(2008) indica que el diario, a través de su narración, posibilita el acceso al mundo personal de los docentes y la explicitación de los dilemas de la práctica. $Y$ en este sentido, utilizado en un contexto de formación, es un instrumento valioso para la evaluación y reajuste de los procesos didácticos y el desarrollo profesional permanente.

\section{DIARIOS DE FORMACIÓN Y AUTOBIOGRAFÍAS EN EL MARCO DE LA FORMACIÓN DE DOCENTES EN CIENCIAS JURÍDICAS}

Para hacer visible lo que sucede en el campo de la formación docente y de su investigación, compartimos algunos ejemplos. Para ello referimos a la investigación realizada en la Facultad de Derecho de la Universidad de Buenos Aires ${ }^{2}$, donde se revelaron y analizaron autobiografías y diarios de formación de abogados que se estaban formando como profesores. Una vez elaboradas, construimos categorías para analizarlas; compartimos una de ellas:

\section{Cuadro 1. Ejemplo de una categoría para analizar las autobiografías escolares.}

\section{DEFINICIÓN DE LA CATEGORÍA}

La categoría estrategias de enseñanza refiere a las acciones de los docentes evocados por los autores de las autobiografías vinculadas a la gestión de la clase, uso de recursos, modos de transmisión de los contenidos, y relación entre enseñanza y evaluación.

\section{INDICADORES}

\section{Fragmentos narrativos que hacen referencia a:}

a) Tipos de actividades que proponen los docentes.

b) Tipos de agrupamiento.

c) Intervenciones del docente apelando al tipo de demanda cognitiva.

d) Uso de recursos.

e) Relaciones entre enseñanza y evaluación.

f) Prácticas de enseñanza valoradas positivamente en la Facultad de Derecho.

Fuente: Elaboración propia. Proyecto UBACYT D411 (2010).

$2 \quad$ Proyecto UBACYT D411. 
A continuación, tomaremos una de las categorías mencionadas en el cuadro, para analizarlas.

\section{- Categoría: Estrategias de enseñanza. Tipos de actividades que proponen los docentes}

En la categoría estrategias encontramos varias referencias al tipo de tareas. Entendemos por tipos de tareas a las diferentes actividades que el docente despliega y propone a los alumnos.

Casi un 50\% de los estudiantes se refiere a la exposición. Hallamos, en algunos casos, referencias a exposiciones claras que mantenían sus docentes, ya sea apelando al sentido del humor como a ejercicios prácticos. También hay quienes recuerdan estas clases expositivas como buenas clases en el sentido de estar bien organizadas. A continuación, presentamos fragmentos de autobiografías que hacen referencia a este aspecto:

- Llegaba puntualmente, se paraba frente a la clase y con voz clara y firme, saludaba, hacía un chiste y luego preguntaba si habíamos comprendido lo que había estado enseñando en la clase anterior. A partir de ahí hacía una breve síntesis y luego comenzaba la nueva clase. La exposición era sencilla, mientras lo hacía establecía contacto visual con los alumnos. Mantenía la atención. Me he preguntado cómo lo lograba, ya que la materia era una de esas que resulta bastante complicada de aprender. Hablaba con voz clara y firme (9).

- La profesora de historia de tercero era historiadora y sobre todo le interesaba la historia económica. Daba clases muy buenas, siempre expositivas, y una eterna muletilla «Eeeeh, ¿verdad?» (2).

Asimismo, encontramos un grupo de alumnos que describe a las exposiciones de los docentes como monólogos en los que no se permitía la participación de los alumnos. Solo en un caso se hace mención a que algunos profesores de la carrera de Derecho, al final de sus exposiciones, preguntaban a los estudiantes si habían comprendido. Hallamos 
referencias a monólogos acompañados por el uso de la pizarra y por preguntas retóricas, interpretadas estas por quien las recuerda, como herramientas para mantener la atención de los alumnos:

- Sus clases eran en el fondo un monólogo, pero para mantener a todo el mundo alerta, iba desgranando preguntas que terminaban siendo retóricas y que abrían paso a la siguiente parrafada (2).

- En muchas de las clases no había posibilidad de hacer preguntas. Es increíble que una carrera de grado, donde se supone debía enseñarnos a pensar en forma crítica para poder hacer frente de mejor modo a la profesión, no se hiciera. La mayoría de las clases estaban estructuradas como una especie de clases magistrales donde el docente venía y repetía una serie de artículos de alguna ley o cuerpo normativo, sin explicar la forma de usarlo en la práctica (11).

Encontramos también una referencia a la exposición acompañada de ejemplos explicativos, aunque, aun así, generaba aburrimiento en los alumnos:

- Las clases eran expositivas; se leía el libro asignado y aunque el Dr. D trataba de ejemplificar las situaciones jurídicas expuestas, con el objeto de signar con una impronta de mayor dinamismo a las clases, la verdad es que resultaban tremendamente aburridas y a fin de cuentas, prescindibles (33).

En relación con los «diarios de formación», construimos las siguientes categorías y compartimos una de ellas: 


\section{Cuadro 2. Ejemplo de una categoría para analizar los diarios de formación.}

\begin{tabular}{|c|c|}
\hline DEFINICIÓN CONCEPTUAL & INDICADORES \\
\hline $\begin{array}{l}\text { La categoría planificación refiere } \\
\text { al diseño de las clases. Se toma en } \\
\text { cuenta tanto el proceso psicológico del } \\
\text { sujeto en su elaboración del plan, como } \\
\text { la planificación en tanto producto e } \\
\text { instrumento de referencia para la acción. }\end{array}$ & $\begin{array}{l}\text { Fragmentos narrativos que dan cuenta de } \\
\text { la enseñanza en su planificación y puesta } \\
\text { en práctica: } \\
\text { a) Los contenidos de la clase. } \\
\text { b) El diseño de las actividades de } \\
\text { aprendizaje. } \\
\text { c) Los recursos utilizados en clase del uso } \\
\text { del tiempo. }\end{array}$ \\
\hline
\end{tabular}

Fuente: Elaboración propia. Proyecto UBACYT D411 (2010).

A continuación, tomaremos una de las categorías mencionadas en el cuadro, para analizarla.

\section{- Categoría: Enseñanza. Planificación y puesta en práctica}

En los diarios analizados se encontraron distintos párrafos que aluden al proceso de planificación y/o a los componentes de la planificación. Algunos apuntan a los contenidos de la clase, otros al diseño de las actividades, a los recursos a utilizar en la clase y al uso del tiempo. Otros párrafos se refieren al proceso psicológico de la planificación y a las tensiones que en el mismo se presentan.

\section{a. Los contenidos de la clase}

En relación con este componente de la planificación, aparecen las deliberaciones acerca de los saberes a enseñar:

- Antes de ponerme a planificar me fui hasta la biblioteca de mi barrio y consulté varios libros de Derecho para observar cómo trataban el 
tema en la escuela media. Percibí que el nivel era bastante más bajo de lo que nosotros habíamos estudiado en la carrera de grado, y que por lo tanto esto era una cuestión no menor a tener en cuenta: el vocabulario y la transposición didáctica. Una vez que ya había analizado todos estos libros de texto, comencé a planificar las clases de las prácticas y evidencié que por lo menos en esta instancia, es algo que lleva tiempo y mucha reflexión, que es trabajoso, pero no algo imposible (32).

- Tercera y última clase [...] pese a que ya conozco el grupo, igualmente me invaden los nervios, ya que debo efectuar un cierre que conglobe los tres temas. Siendo el tema el de Estado Neoliberal y Estado Keynesiano efectuaré un cuadro que tratará de sintetizar lo visto y darle un marco de contexto de surgimiento y evolución (29).

- Los contenidos que debo impartir no son, por sí, difíciles ni complicados [...] para mí. Con sólo leer el Código Civil logré actualizarlos en mi cabeza, pero [...] acá surgió un nuevo obstáculo: ¿Cómo hacer para que conceptos tan simples para mi estructura mental, como lo son la definición de persona y atributos de la personalidad en el Código Civil, se conviertan en asequibles para chicos de 16 años? (18).

Se observa la preocupación por la extensión y el nivel de complejidad de los contenidos. Aparecen aquí alusiones a la distancia entre lo estudiado en la Facultad, lo que establece el programa del curso del que deben hacerse cargo y los conocimientos previos de los alumnos. Otra tensión se presenta en la jerarquización y recorte de la información y aparecen también los propios intereses y posiciones del practicante frente al tema asignado que, en algunos casos no es de su especialidad, no recuerda o no acuerda. Estos problemas sitúan a los futuros profesores en la necesidad de realizar sus primeras transposiciones didácticas (alguno de los autores de los diarios lo consigna explícitamente) y los confronta con la vigilancia epistemológica, y la relación con el propio saber.

En las historias de vida hallamos quiebres, nudos problemáticos, ambigüedades, dificultades electivas, valoraciones en pugna, 
la revelación de que en uno mismo puede habitar más de un personaje con diferentes miradas sobre la realidad y sobre uno mismo, y percatarse de que en una vida hay trabajo incesante para dar coherencia a conductas y puntos de vista.

Contursi y Ferro (2000), investigadoras del campo de la lingüística, nos aportan ideas acerca de la contribución de las narrativas:

[...] Pero la narrativa no es solo una forma de inteligibilidad, sino que, en su dimensión comunicativa, es también una práctica socialmente simbólica en la que se pueden distinguir dos características fundamentales: adquieren sentido solo en un contexto social y, a la vez, contribuyen a la construcción de ese contexto social como espacio de significación en el que están involucrados los sujetos (p. 101).

Se trata de sujetos sociales, docentes, dentro de un espacio social y político, en un tiempo particular, que reciben influencias o son determinados en el qué y el cómo de sus narraciones y que, a su vez, a través de estos relatos, pueden producir modificaciones sobre la enseñanza.

Cabe señalar que aunque muchos docentes se consideren practicantes reflexivos, es necesario acompañar el recorrido para favorecer una reflexión profunda. Coincidimos con Clandinin y Connelly (1995) que, facilitando los espacios de reflexión, es posible dar cuenta que también las emociones tienen impacto sobre las decisiones acerca de las prácticas de enseñanza que se llevan adelante. Crear espacios reflexivos, poniendo en juego el uso de narrativas de las experiencias en clase, posibilita profundizar las comprensiones sobre la práctica. Compartir las narrativas con otros muestra y comunica la experiencia, y los diálogos de reflexión compartida con colegas permitirían desafiar creencias, opiniones, y suposiciones sobre la enseñanza. 


\section{REFERENCIAS}

Anijovich y Cappelletti (2011). La formación docente en Ciencias Jurídicas: dispositivos para la práctica reflexiva. Espacios en Blanco. Revista de Educación, 21.

Alliaud, A., y Suárez, D. (2011). El saber de la experiencia. Narrativa, investigación y formación docente. Buenos Aires: Facultad de Filosofía y Letras y CLACSO.

Arfuch, L. (2002). El espacio biográfico: dilemas de la subjetividad contemporánea (No. 165.722). Fondo de Cultura Económica.

Beristain, H. (1995). Diccionario de retórica y poética. México: Porrúa.

Bolívar, A. D., y Domingo, J. J. y Fernández, M.(2001). La investigación biográfico-narrativa en educación. Enfoque y metodología.

Bruner, J. (1987). Realidad mental y mundos posibles. Barcelona: Gedisa.

Bruner, J. (1990). Actos de significado. Madrid: Gedisa.

Bruner, J. y Weisser, S. (1991). La invención del yo: la autobiografía y sus formas. En Olson, D. y Torrance, N. (comps.) Cultura escrita y oralidad. Barcelona: Gedisa. 1995. pp. 177-202.

Carretero, M. y Atorresi, A. (2004). «El pensamiento narrativo» en Carretero y Asensio, Psicología del pensamiento. Madrid: Alianza.

Casares, J. (1984). Diccionario ideológico de la lengua española. Barcelona: Editorial Gilli.

Cochran-Smith \& Lytle (1990). Research on teaching and teacher research: The Issues that divide. Educational Researcher 19(2) 2-11.

Clandinin, J. (2002). Stories lives on storied landscapes. Curriculum and teacher dialogue. 4(1). Universidad de Alberta. 
Clandinin, D. J., \& Connelly, F. M. (1995). Teachers' professional knowledge landscapes. Teachers College Press.

Contursi, M. y Ferro, F. (2000). La narración-Usos y teorías. Buenos Aires: Editorial Norma.

Diccionario de términos literarios (1990). Akal.

Elbaz, F. (2002). Writing as inquiry: storing the teaching self in writing workshops. Curriculum Inquiry 32:4. Ontario Institute for Studies in Education.

Gudmundsdottir, S. (1998). La naturaleza narrativa del saber pedagógico sobre los contenidos en McEwan, H. y Kieran, E. La narrativa en la enseñanza, el aprendizaje y la investigación. Buenos Aires: Amorrortu.

Lawrence-Lightfoot \& J. H. Davis, The art and science of portraiture. San Francisco, CA: Jossey-Bass.

McEwan, H. y Egan, E. (1997). La narrativa en la enseñanza, el aprendizaje y la investigación. Buenos Aires: Amorrortu.

Moliner, M. (1991): Diccionario del uso del español. Madrid: Editorial Gredos.

Pinar, W. F., \& Grumet, M. R. (1976). Toward a poor curriculum. Dubuque, IA: Kendall/Hunt.

Porlán, R. (1999). Investigar la práctica. Cuadernos de pedagogía, (276), 48-49.

Plummer K., y Cobelo, J. V. (1989). Los documentos personales: Introducción a los problemas y la bibliografía del método humanista. Siglo XXI de España. 
Ricoeur, P. (1984). Técnica y no-técnica en la interpretación. Hermenéutica y psicoanálisis.

Richardson, L. (1997). Fields of play: Constructing an academic life. New Brunswick, NJ: Rutgers University Press.

Riessman, C. K. (1993). Narrative analysis. Newbury Park, CA: Sage.

Suárez, D. H. (2011). «Relatos de experiencia, saber pedagógico y reconstrucción de la memoria escolar». Educação em Revista, 27(1), 387416.

Zabalza, M. A. (2007). Buenas prácticas en el Practicum: bases para su identificación y análisis. CID, A. et al., Buenas prácticas en el Prácticum. Santiago de Compostela: Imprenta universitaria. 